\title{
Diagnostic performance of thyroid ultrasound in Hürthle cell carcinomas
}

Nathalie Oliveira Santana', Ricardo Miguel Costa Freitas², Vinicius Neves Marcos², Maria Cristina Chammas', Rosalinda Yossie Asato Camargo', Cláudia Kliemann Schmerling ${ }^{4}$, Felipe Augusto Brasileiro Vanderlei ${ }^{5}$, Ana Oliveira Hoff ${ }^{6}$, Suemi Marui', Debora Lucia Seguro Danilovic ${ }^{1,6}$

\begin{abstract}
Objective: Hürthle cell carcinomas (HCCs) of the thyroid have been recently reclassified as a separate entity due to their distinct clinical and molecular profiles. Few studies have assessed the ability of preoperative characteristics in differentiating HCCs from Hürthle cell adenomas (HCAs) due to the low prevalence of both lesions. This study aimed to compare the preoperative features of HCCs and HCAs and evaluate the diagnostic performance of ultrasound in distinguishing between both. Subjetcs and methods: Retrospective study including 101 patients (52 HCCs and 49 HCAs) who underwent thyroid surgery from 2000 to 2016. Clinical, ultrasonographic, and histological data were reviewed. Diagnostic performance of suspicious sonographic features was analyzed in 51 cases (24 HCCs and 27 HCAs). Results: Hürthle cell neoplasms were predominant in females. Subjects $\geq 55$ years represented $58 \%$ of the cases of HCCs and $53 \%$ of those of HCAs. Carcinomas were significantly larger $(\mathrm{p}<0.001$ ), and a tumor size $\geq 4 \mathrm{~cm}$ significantly increased the risk of malignancy (odds ratio 3.67). Other clinical, cytologic, and sonographic data were similar between HCCs and HCAs. Among the HCCs, the lesions were purely solid in $54.2 \%$, hypoechoic in $37.5 \%$, and had coarse calcifications in $12.5 \%$, microcalcifications in $8.3 \%$, irregular contours in $4.2 \%$, and a taller-than-wide shape in $16.7 \%$. Predominantly/exclusive intranodular vascularization was observed in $52.6 \%$. Overall, $58 \%$ of the HCCs were classified asTI-RADS 4 or 5 compared with $48 \%$ of the HCAs. TI-RADS 4 or 5 had a specificity of only $51.8 \%$ and a positive likelihood ratio of 1.21 . Conclusions: Apart from the lesion size, no other preoperative feature adequately distinguished HCCs from HCAs. Sonographic characteristics raising suspicion for malignancy, which are mostly present in papillary carcinomas, were infrequent in HCCs. New tools must be developed to improve preoperative diagnosis and deferral of surgery in cases of adenomas. Arch Endocrinol Metab. 2019;63(3):300-5
\end{abstract}

Keywords

Ultrasound; thyroid cancer; Hürthle cell; Doppler
${ }^{1}$ Laboratório de Endocrinologia Celular e Molecular (LIM25), Hospital das Clínicas da Faculdade de Medicina, Universidade de São Paulo, São Paulo, SP, Brasil 2 Radiologia, Instituto do Câncer do Estado de São Paulo, Faculdade de Medicina, Universidade de São Paulo, São Paulo, SP, Brasil ${ }^{3}$ Radiologia, Instituto de Radiologia (InRad), Hospital das Clínicas da Faculdade de Medicina, Universidade de São Paulo, São Paulo, SP, Brasil

4 Departamento de Patologia, Instituto do Câncer do Estado de São Paulo, Faculdade de Medicina, Universidade de São Paulo, São Paulo, SP, Brasil 5 Departamento de Cirurgia de Cabeça e Pescoço, Hospital das Clínicas da Faculdade de Medicina, Universidade de São Paulo, São Paulo, SP, Brasil ${ }^{6}$ Departamento de Endocrinologia, Instituto do Câncer do Estado de São Paulo, Faculdade de Medicina, Universidade de São Paulo, São Paulo, SP, Brasil

Correspondence to:

Debora Lucia Seguro Danilovic Laboratório de Endocrinologia Celular e Molecular (LIM25), Hospital das Clínicas, Faculdade de Medicina, Universidade de São Paulo, Av. Dr. Arnaldo, 455, sala 4305 01246-903 - São Paulo, SP, Brasil deboradanilovic@usp.br

Received on Jan/16/2019 Accepted on Feb/27/2019 DOI: $10.20945 / 2359-3997000000131$

\section{INTRODUCTION}

$\mathrm{T}$ hyroid carcinomas have increased in prevalence over the last decades (1). Papillary and follicular thyroid cancers are the most common histological types of thyroid cancer, while Hürthle cell carcinomas (HCCs) correspond to only 3 to $4 \%$ of all thyroid malignancies. Due to their distinct clinical behavior, HCCs have been recently reclassified as a separate entity $(2,3)$.

A thyroid tumor is classified as a Hürthle cell neoplasm $(\mathrm{HCN})$ when over $75 \%$ of its tumor cells display oncocytic histologic features without nuclear characteristics of papillary carcinoma. These so-called Hürthle cells are found not only in $\mathrm{HCN}$, but also in benign lesions like nodular goiter, Graves' disease, and Hashimoto's thyroiditis, as well as after cervical radiotherapy. Oncocytic changes were previously considered to be a consequence of cellular senescence, but are now seen as a metaplastic process in response to a variety of stimuli inducing cellular stress (4-6).

Similar to follicular neoplasms, HCCs are distinguished from Hürthle cell adenomas (HCAs) by the presence on histological assessment of vascular and capsular invasion or identification of nodal and/or distant metastases (4). HCCs are classified as minimally or widely invasive, the last one presenting a poorer response to radioactive iodine therapy and higher recurrence 
and mortality rates (7-11). Fine-needle aspiration biopsy (FNA) of HCNs are usually indeterminate for malignancy, challenging the preoperative diagnosis of HCCs. Even current molecular preoperative tests are unable to distinguish HCNs and HCCs correctly (12). Therefore, surgery is still required to distinguish benign and malignant HCNs (13-15).

Only a few studies have reported the imaging findings of Hürthle cell tumors. Besides, due to their rarity, HCCs have been poorly represented in these studies, and their sonographic features have been analyzed in combination with those of adenomas (16-21).

The aims of this study were to compare the clinical presentation of HCCs and HCAs and evaluate the impact of thyroid ultrasound in distinguishing one lesion from another.

\section{SUBJECTS AND METHODS}

\section{Subjects}

This retrospective study included 101 patients with pathologically proven HCNs who underwent total thyroidectomy or lobectomy in a tertiary center from 2000 to 2016. Clinical, cytologic, and histopathologic data were collected by retrospective chart review. The histopathology of the lesions was reassessed by a pathologist.

The study was approved by the Research Ethics Committee of the University of São Paulo. Data were analyzed anonymously, and any identifying marks in the ultrasound images were removed.

\section{Methods}

Preoperative ultrasound images were available in 51 cases (24 HCCs and 27 HCAs). Gray-scale and color Doppler images were obtained using high-frequency transducers $(7.5-12 \mathrm{MHz})$ with the following US equipment models: iU22 (Philips, Eindhoven, The Netherlands), MyLab 70XV (Esaote, Florence, Italy), Sonix (Ultrasonix, Burnaby, Canada), Aplio 500 (Toshiba Medical Systems, Tokyo, Japan), or Logic E9 (GE Healthcare, Milwaukee, Wisconsin, USA). Two blinded radiologists retrospectively analyzed the sonographic imaging characteristics and, when their diagnoses were discordant, a third radiologist reviewed the images. The following nodular features were evaluated: size, echogenicity, solid and/or cystic aspect, contours, presence of a hypoechoic peripheral halo (rim) or calcifications, vascularization pattern, and presence of atypical lymph nodes. We compared the longest diameter of the lesions, and evaluated if the nodular height was greater than the width. The echogenicity of the nodule was assessed in relation to the normal thyroid parenchyma. The margins of the nodules were classified as regular or irregular. Microcalcifications were defined as hyperechoic foci up to $2 \mathrm{~mm}$ in size, while coarse calcifications were defined as hyperechoic foci > $2 \mathrm{~mm}$ in size with posterior acoustic shadowing. The type of vascularization was classified as peripheral, if the vascularization was predominantly perinodular, or central, if it was predominantly intranodular.

We analyzed the diagnostic performance of the following features of malignancy suspicion in HCCs: hypoechogenicity, solid aspect, irregular contours, absence of a hypoechoic peripheral halo, presence of microcalcifications or coarse calcifications, taller-thanwide shape, and intranodular vascularization pattern.

The nodules were classified according to the Thyroid Imaging, Reporting and Data System (TI-RADS) (22). The diagnostic performance of HCCs in the TI-RADS 4 and 5 categories, which correspond to moderately and highly suspicious nodules, respectively, was also evaluated.

\section{Statistical analysis}

The data were processed using IBM SPSS Statistics for Windows, Version 24.0 (IBM Corp., Armonk, New York, USA). Two-tailed $p$ values were used, and values $<0.05$ were considered statistically significant.

Categorical variables are presented as absolute and relative (percentages) frequencies. Differences were evaluated by Pearson's chi-square test and Fisher's exact test, when appropriate. Continuous variables are presented as mean \pm standard deviation values. Differences among study subgroups were determined using Student's $t$ test, for normal distributions, or Mann-Whitney U test for non-normal distributions.

The diagnostic performance (sensitivity, specificity, positive likelihood ratio [LR], negative LR) of the thyroid ultrasound exams was analyzed. We defined the true positive, true negative, false positive, and false negative results based on the final histological diagnosis (carcinoma or adenoma).

\section{RESULTS AND DISCUSSION}

Data from 52 HCCs and 49 HCAs were available for review. No significant clinical differences were 
observed between benign and malignant cases. HCNs predominated in female subjects $(83 \%$ HCCs vs. $84 \%$ HCAs). The mean age of the patients was $57.2 \pm 14.5$ years in malignant and $55.2 \pm 13.3$ years in benign cases. Subjects aged $\geq 55$ years comprised $58 \%$ of the patients with HCC and $53 \%$ of those with HCA. The mean preoperative TSH level was $1.9 \pm 1.5 \mu \mathrm{U} / \mathrm{mL}$ in patients with $\mathrm{HCC}$ and $2.1 \pm 1.2 \mu \mathrm{U} / \mathrm{mL}$ in those with HCA.

On pathological analysis, the diameter of the carcinomas was significantly larger (mean $47.4 \pm 25.7$ $\mathrm{mm}$, median $46.5 \mathrm{~mm}$ ) than that of the adenomas (mean $28.6 \pm 19.5 \mathrm{~mm}$, median $25 \mathrm{~mm}$; p $<0.001$ ). Nodules $\geq 4 \mathrm{~cm}$ had an increased risk of malignancy (odds ratio $3.67,95 \%$ confidence interval 1.58 8.52) (Figure 1). Multinodular goiter coexisted in $51 \%$ of the carcinomas and $40.8 \%$ of the adenomas, while lymphocytic thyroiditis was found in $15.7 \%$ and $14.3 \%$ of the carcinomas and adenomas, respectively. Coexisting papillary thyroid carcinoma was diagnosed in $16 \%$ of the subjects with HCC and $20.4 \%$ of those with HCA. One patient with HCC had a concomitant poorly differentiated thyroid carcinoma.

All HCCs presented as unifocal lesions, and 52.6\% of the HCCs were considered widely invasive. Vascular invasion was present in $76 \%$ and extrathyroidal extension in $6.5 \%$ of the HCCs. Lymph node metastases were diagnosed in 5 cases (10\%), while 6 patients $(12 \%)$ had distant metastases.

The mean largest dimensions of the carcinomas and adenomas on the ultrasound images were $50.1 \pm$
28.3 vs. $37.9 \pm 22.5 \mathrm{~mm}(\mathrm{p}=0.05)$, respectively. The ultrasound features of HCCs and HCAs are described in Table 1; no significant differences were observed between the groups. A wide spectrum of sonographic patterns was observed in carcinomas (Figure 2). A cytological diagnosis of follicular neoplasm/HCN (Bethesda IV) was observed in $87.2 \%$ of HCC and $96.7 \%$ of HCA cases (Table 2). The diagnostic performance of ultrasound in HCC is presented in Table 3.

Hypoechogenicity and presence of coarse calcifications had the highest positive LR. However, the specificity of hypoechogenicity was only $77.8 \%$. Also, despite having high specificity, the presence of coarse calcifications was observed in only $12.5 \%$ of the HCCs.

We also evaluated the diagnostic performance of the TI-RADS classification in HCCs. Even though $58 \%$ of the HCCs were classified as TI-RADS 4 or 5 , no significant difference was observed in this regard when HCCs were compared with HCAs, as $48 \%$ of the latter cases were also moderately or highly suspicious. Therefore, TI-RADS 4 or 5 had a specificity of only $51.8 \%$ and a positive LR of 1.21 .

Apart from tumor size, no significant difference occurred between benign and malignant cases that could allow an accurate preoperative diagnosis. In this series, Hürthle cell tumors larger than $4 \mathrm{~cm}$ had a significantly increased malignancy risk, which reinforces data from a recent report of 330 pathologically diagnosed oxyphilic cell neoplasms (61 carcinomas), in which a tumor size $>4 \mathrm{~cm}$ was an independent predictor of HCC (23).

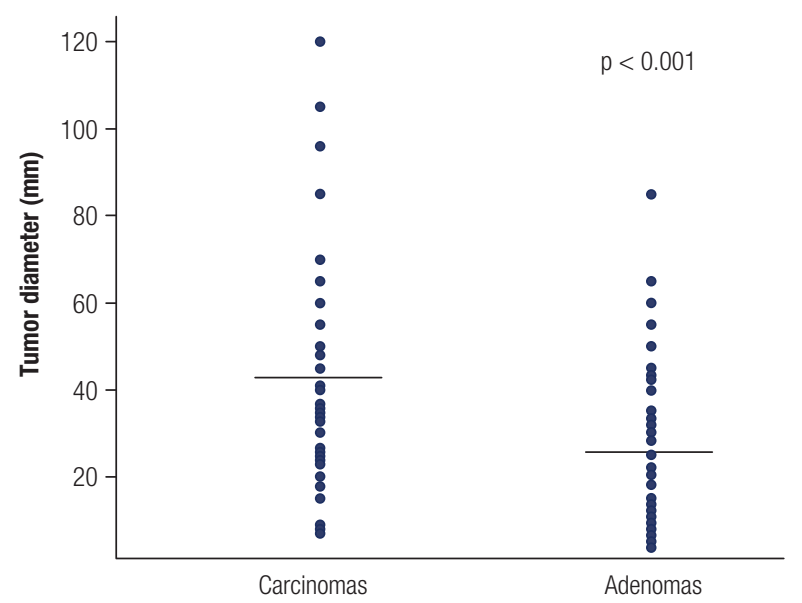

Figure 1. Comparison of the largest diameters of Hürthle cell carcinomas and adenomas. The solid lines represent the median diameter of the carcinomas and adenomas.
Table 1. Ultrasound characteristics of Hürthle cell carcinomas and adenomas

\begin{tabular}{lcc}
\hline Ultrasound characteristic & $\begin{array}{c}\text { Carcinoma } \\
(\mathbf{n}=\mathbf{2 4})\end{array}$ & $\begin{array}{c}\text { Adenoma } \\
(\mathbf{n}=\mathbf{2 7})\end{array}$ \\
\hline Hypoechogenicity (\%) & $9(37.5)$ & $6(22.2)$ \\
Purely solid (\%) & $13(54.2)$ & $12(44.4)$ \\
Irregular contours (\%) & $1(4.2)$ & $3(11.1)$ \\
Absence of hypoechoic halo (\%) & $5(20.8)$ & $11(40.7)$ \\
Microcalcification (\%) & $2(8.3)$ & $3(11.1)$ \\
Coarse calcification (\%) & $3(12.5)$ & $2(7.4)$ \\
Taller-than-wide shape (\%) & $4(16.7)$ & $8(29.6)$ \\
Central or predominantly central blood flow (\%)* & & \\
TI-RADS & $10(52.6)$ & $12(60)$ \\
2 & $5(20.8)$ & $4(14.8)$ \\
3 & $5(20.8)$ & $10(37)$ \\
4 & $12(50)$ & $10(37)$ \\
5 & $2(8.3)$ & $3(11.1)$ \\
\hline
\end{tabular}

* Percentage from available exams. 

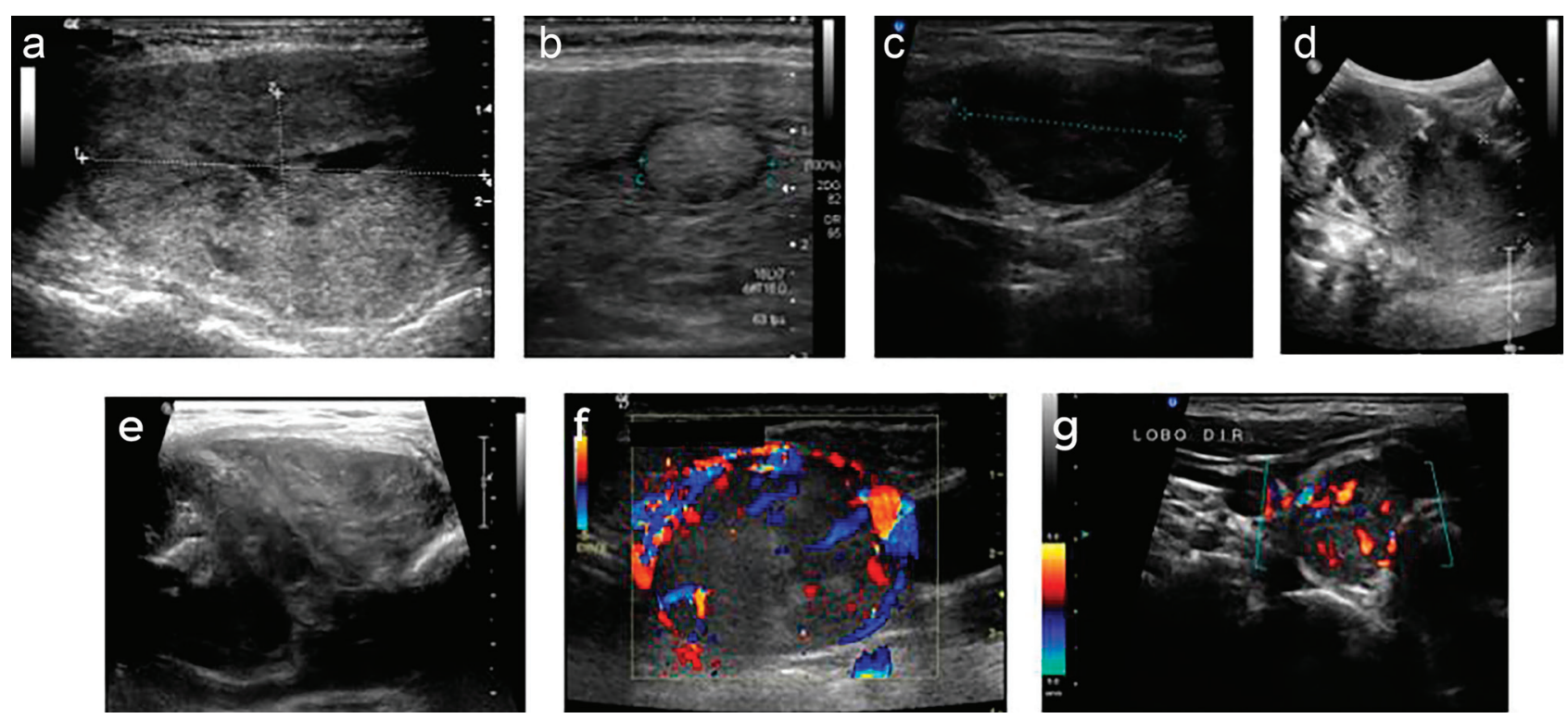

Figure 2. Variety of sonographic presentations of Hürthle cell carcinomas. (A) Partially cystic isoechoic nodule; (B) solid isoechoic nodule with peripheral halo; (C) markedly solid hypoechoic nodule; (D) solid hypoechoic nodule with coarse calcifications; (E) solid hypoechoic nodule with microcalcifications and coarse calcifications; (F) solid isoechoic nodule with peripheral vascularization; (G) solid hypoechoic nodule with intranodular vascularization.

Table 2. Thyroid cytopathology of Hürthle cell carcinomas and adenomas

\begin{tabular}{lccc}
\hline Cytopathology & $\begin{array}{c}\text { Carcinomas } \\
(\mathbf{n = 3 8 )}\end{array}$ & $\begin{array}{c}\text { Adenomas } \\
(\mathbf{n = 3 0})\end{array}$ & p value \\
\hline Benign & $4(10.5 \%)$ & $1(3.3 \%)$ & 0.156 \\
Follicular neoplasm or suspicious for follicular neoplasm & $9(23.7 \%)$ & $12(40 \%)$ & 0.231 \\
Follicular neoplasm or suspicious for follicular neoplasm, & $24(63.1 \%)$ & $17(56.6 \%)$ & 0.587 \\
Hürthle cell & & - & - \\
Nondiagnostic or unsatisfactory & $1(2.7 \%)$ & \\
\hline
\end{tabular}

Table 3. Performance of sonographic features raising suspicion for malignancy in the diagnosis of Hürthle cell carcinomas

\begin{tabular}{|c|c|c|c|c|c|}
\hline $\begin{array}{l}\text { Ultrasound } \\
\text { characteristic }\end{array}$ & $\begin{array}{l}\text { Sensitivity } \\
\text { (95\% Cl) }\end{array}$ & $\begin{array}{l}\text { Specificity } \\
\text { (95\% Cl) }\end{array}$ & $\begin{array}{c}\text { Positive } \\
\text { LR } \\
\text { (95\% Cl) }\end{array}$ & $\begin{array}{c}\text { Negative } \\
\text { LR } \\
(95 \% \mathrm{Cl})\end{array}$ & $\begin{array}{l}\text { Accuracy } \\
(95 \% \mathrm{Cl})\end{array}$ \\
\hline Hypoechogenicity & $\begin{array}{c}37.5 \% \\
(18.80-59.41)\end{array}$ & $\begin{array}{c}77.8 \% \\
(57.74-91.38)\end{array}$ & $\begin{array}{c}1.69 \\
(0.70-4.05)\end{array}$ & $\begin{array}{c}0.8 \\
(0.56-1.16)\end{array}$ & $\begin{array}{c}58.8 \% \\
(44.17-72.42)\end{array}$ \\
\hline Purely solid & $\begin{array}{c}54.2 \% \\
(32.82-74.45)\end{array}$ & $\begin{array}{c}55.6 \% \\
(35.33-74.52)\end{array}$ & $\begin{array}{c}1.22 \\
(0.70-2.13)\end{array}$ & $\begin{array}{c}0.83 \\
(0.48-1.43)\end{array}$ & $\begin{array}{c}54.9 \% \\
(40.34-68.87)\end{array}$ \\
\hline Irregular contours & $\begin{array}{c}4.2 \% \\
(0.11-21.12)\end{array}$ & $\begin{array}{c}88.9 \% \\
(70.84-97.65)\end{array}$ & $\begin{array}{c}0.37 \\
(0.04-3.37)\end{array}$ & $\begin{array}{c}1.08 \\
(0.92-1.26)\end{array}$ & $\begin{array}{c}49 \% \\
(34.75-63.40)\end{array}$ \\
\hline Absence of peripheral halo & $\begin{array}{c}20.8 \% \\
(7.13-42.15)\end{array}$ & $\begin{array}{c}59.3 \% \\
(38.80-77.61)\end{array}$ & $\begin{array}{c}0.51 \\
(0.21-1.26)\end{array}$ & $\begin{array}{c}1.34 \\
(0.92-1.94)\end{array}$ & $\begin{array}{c}41.2 \% \\
(27.58-55.83)\end{array}$ \\
\hline Microcalcification & $\begin{array}{c}8.3 \% \\
(1.03-27.00)\end{array}$ & $\begin{array}{c}88.9 \% \\
(70.84-97.65)\end{array}$ & $\begin{array}{c}0.75 \\
(0.14-4.12)\end{array}$ & $\begin{array}{c}1.03 \\
(0.86-1.23)\end{array}$ & $\begin{array}{c}51 \% \\
(36.60-65.25)\end{array}$ \\
\hline Coarse calcification & $\begin{array}{c}12.5 \% \\
(2.66-32.36)\end{array}$ & $\begin{array}{c}92.6 \% \\
(75.71-99.09)\end{array}$ & $\begin{array}{c}1.69 \\
(0.31-9.26)\end{array}$ & $\begin{array}{c}0.94 \\
(0.79-1.14)\end{array}$ & $\begin{array}{c}54.9 \% \\
(40.34-68.87)\end{array}$ \\
\hline Taller-than-wide shape & $\begin{array}{c}16.7 \% \\
(4.74-37.38)\end{array}$ & $\begin{array}{c}70.4 \% \\
(49.82-86.25)\end{array}$ & $\begin{array}{c}0.56 \\
(0.19-1.63)\end{array}$ & $\begin{array}{c}1.18 \\
(0.87-1.60)\end{array}$ & $\begin{array}{c}45.1 \% \\
(31.13-59.66)\end{array}$ \\
\hline $\begin{array}{l}\text { Central or predominantly } \\
\text { central blood flow }\end{array}$ & $\begin{array}{c}50 \% \\
(27.20-72.80)\end{array}$ & $\begin{array}{c}36.8 \% \\
(16.29-61.64)\end{array}$ & $\begin{array}{c}0.79 \\
(0.45-1.38)\end{array}$ & $\begin{array}{c}1.36 \\
(0.65-2.83)\end{array}$ & $\begin{array}{c}43.6 \% \\
(27.81-60.38)\end{array}$ \\
\hline TI-RADS 4 or 5 & $\begin{array}{c}58.3 \% \\
(36.64-77.89)\end{array}$ & $\begin{array}{c}51.9 \% \\
(31.95-71.33)\end{array}$ & $\begin{array}{c}1.21 \\
(0.72-2.03)\end{array}$ & $\begin{array}{c}0.8 \\
(0.44-1.46)\end{array}$ & $\begin{array}{c}54.9 \% \\
(40.34-68.87)\end{array}$ \\
\hline
\end{tabular}

LR: likelihood ratio; 95 \% Cl: 95\% confidence interval. 
Other studies have also demonstrated a correlation between tumor size and malignancy risk in HCNs. A tumor size $\geq 2.5 \mathrm{~cm}$ was an independent predictor of HCC (24), whereas all tumors $\leq 2 \mathrm{~cm}$ observed were benign and all of those larger than $6 \mathrm{~cm}$ were malignant (25).

As previously demonstrated, the cytologic analysis of our tumors failed to identify malignant nodules correctly, as $87 \%$ of the HCCs and $97 \%$ of the HCAs were diagnosed as follicular neoplasm/HCN (Bethesda IV). The positive predictive value for malignancy of cytologic $\mathrm{HCN}$ diagnoses has been previously described to be between 15 and $45 \%(13,15)$, decreasing to 9.5\% in the presence of Hashimoto's thyroiditis (14). Therefore, other preoperative aspects should be evaluated to allow a proper diagnosis of malignancy before surgery.

Several sonographic features are usually associated with a higher risk of malignancy in a thyroid nodule. According to the American Thyroid Association, a highly suspicious sonographic pattern is represented by a solid hypoechoic nodule or solid hypoechoic component of a partially cystic nodule associated with at least one of the following findings: irregular margins, microcalcifications, taller-than-wide shape, rim calcifications with a small protruding soft tissue component or evidence of extrathyroidal extension. The absence of a peripheral halo and increased intranodular vascularization are also considered suspicious for malignancy (1). These suspicious characteristics are mainly observed in papillary thyroid carcinomas $(1,26)$.

In this retrospective analysis, B-mode and color Doppler sonographic features were unable to differentiate malignant from benign $\mathrm{HCNs}$. HCNs may present a wide variety of sonographic findings (16$20,24,27)$, and hypoechogenicity predicted malignancy in this background (28). Ito and cols. (23) observed that round and hypoechoic solid nodules and solid nodules with irregular borders or with psammoma calcifications represented $83 \%$ of the carcinomas and $78 \%$ of the adenomas. However, the authors concluded that such sonographic presentations were independent predictors of malignancy in patients with Hürthle cells in FNA cytology. In contrast, lesions with a flat, isoechoic, or hyperechoic pattern with a peripheral halo were frequent among the HCCs in the present study at rates of $83.3 \%, 62.5 \%$, and $79.2 \%$, respectively.

The sonographic features of follicular thyroid carcinomas are different from those of papillary carcinomas. The most frequent presentation of follicular carcinomas (with respective presentation rates for each feature) is as a solid (82.6\%), flat $(72.7 \%)$, isoechoic $(65.2 \%)$ nodule with a hypoechoic rim $(86.6 \%)$ and without calcifications $(82.6 \%)(26)$. The peripheral halo has been suggested to represent the tumor's capsule or pseudocapsule of surrounding fibrous connective tissue, which could be present in both benign and malignant HCNs (19). Unlike previous data on follicular carcinomas (26), cystic changes $(45.8 \%)$ and calcifications, mainly coarse ones $(12.5 \%)$, were observed in our HCCs. Lee and cols. (19) reported cystic changes in around $50 \%$ and coarse calcifications in $20 \%$ of $\mathrm{HCNs}$, without significant differences between benign and malignant nodules, although the authors analyzed a smaller sample of only 3 HCC. Regarding vascularization, our study showed predominantly intranodular vascularization in both HCCs (52.6\%) and HCAs (60\%).

We evaluated the performance of the TIRADS classification in diagnosing HCCs (22). TI-RADS 4 (moderately suspicious) or TI-RADS 5 (highly suspicious) nodules corresponded to $58.3 \%$ of our HCCs. However, $48 \%$ of the HCAs were also categorized as moderately or highly suspicious according to this classification. Likewise, the Korean TIRADS was also unable to distinguish HCCs from HCAs (29).

This study has some limitations. The retrospective analysis was restricted to pathologically proven HCNs, instead of considering all nodules suspected of HCNs on cytology. Although this series included a higher number of HCCs than other reports (due to the rarity of these tumors), the number of cases could be considered small to identify statistically significant differences.

In conclusion, apart from tumor size, no other preoperative feature was able to differentiate HCCs from HCAs adequately. Sonographic characteristics considered suspicious for malignancy, which are mostly seen in papillary thyroid carcinomas, were infrequent in HCCs. Besides, the combination of suspicious sonographic characteristics with the TI-RADS classification was also insufficient to diagnose the cases of HCC accurately. Therefore, new tools must be developed, such as molecular tests or other imaging tools like elastography or contrast-enhanced ultrasound, to allow an accurate preoperative diagnosis of malignancy and possibly defer diagnostic surgery in cases of adenomas. 
Authorship: NOS, RYAC, FABV, and SM collected, analyzed, and interpreted the clinical, cytologic, and sonographic data. RMCF, VNM, and MCC reviewed and analyzed the ultrasound images. CKS reassessed and interpreted the histopathology of the lesions. DLSD conceived the study and its design and performed the statistical analysis. NOS, AOH, SM, and DLSD analyzed and interpreted the compiled data. NOS and DLSD prepared the figures and drafted the main manuscript text. All authors provided critical review and approved the final version of this manuscript.

Acknowledgments: we thank our patients and all the colleagues who contributed to our work.

Funding statement: this research was funded by a grant from Fundação de Amparo à Pesquisa do Estado de São Paulo (FAPESP), grant number 2015/14819-7.

Disclosure: no potential conflict of interest relevant to this article was reported.

\section{REFERENCES}

1. Haugen BR, Alexander EK, Bible KC, Doherty GM, Mandel SJ, NikiforovYE, et al. 2015 American Thyroid Association Management Guidelines for Adult Patients with Thyroid Nodules and Differentiated Thyroid Cancer: The American Thyroid Association Guidelines Task Force on Thyroid Nodules and Differentiated Thyroid Cancer. Thyroid. 2016;26(1):1-133.

2. Lloyd R, Osamura R, Kloppel G. WHO Classification of Tumours: Pathology and Genetics of Tumours of Endocrine Organs. 4a. Lyon, France: IARC; 2017.

3. Hundahl SA, Fleming ID, Fremgen AM, Menck HR. A National Cancer Data Base report on 53,856 cases of thyroid carcinoma treated in the U.S., 1985-1995. Cancer. 1998;83(12):2638-48.

4. Auger M. Hürthle cells in fine-needle aspirates of the thyroid: $A$ review of their diagnostic criteria and significance. Cancer Cytopathol. 2014;122(4):241-9.

5. Cannon J. The Significance of Hurthle Cells in Thyroid Disease. Oncologist. 2011;16:1380-7.

6. Mete O, Asa SL. Oncocytes, oxyphils, hürthle, and askanazy cells: Morphological and molecular features of oncocytic thyroid nodules. Endocr Pathol. 2010;21(1):16-24.

7. Carcangiu ML, Bianchi S, Savino D, Voynick IM, Rosai J. FollicuIar Hurthle cell tumors of the thyroid gland. Cancer. 1991;68(9): 1944-53.

8. Kushchayeva Y, Duh QY, Kebebew E, Clark OH. Prognostic indications for Hürthle cell cancer. World J Surg. 2004;28(12):1266-70.

9. Lopez-Penabad L, Chiu AC, Hoff AO, Schultz P, Gaztambide S, Ordoñez NG, et al. Prognostic factors in patients with Hürthle cell neoplasms of the thyroid. Cancer. 2003;97(5):1186-94.

10. Chindris A-M, Casler JD, Bernet VJ, Rivera M, Thomas C, Kachergus JM, et al. Clinical and Molecular Features of Hürthle Cell Carcinoma of the Thyroid. J Clin Endocrinol Metab. 2015;100(January):55-62.

11. Besic N, Vidergar-Kralj B, Frkovic-Grazio S, Movrin-Stanovnik T, Auersperg M. The Role of Radioactive lodine in the Treatment of Hürthle Cell Carcinoma of the Thyroid. Thyroid. 2003 Jun [cited 2018 Oct 14];13(6):577-84.

12. Harrell R, Bimston D. Surgical Utility of Afirma: Effects of High Cancer Prevalence and Oncocytic CellTypes in Patients with Indeterminate Thyroid Cytology. Endocr Pract. 2014 Apr;20(4):364-9.
13. Pu RT, Yang J, Wasserman PG, Bhuiya T, Griffith KA, Michael CW. Does Hurthle cell lesion/neoplasm predict malignancy more than follicular lesion/neoplasm on thyroid fine-needle aspiration? Diagn Cytopathol. 2006 May;34(5):330-4.

14. Roh MH, JoVY, Stelow EB, Faquin WC, Zou KH, Alexander EK, et al. The predictive value of the fine-needle aspiration diagnosis "Suspicious for a follicular neoplasm, Hürthle cell type" in patients with Hashimoto thyroiditis. Am J Clin Pathol. 2011;135(1):139-45.

15. Giorgadze T, Rossi ED, Fadda G, Gupta PK, Livolsi VA, Baloch Z. Does the fine-needle aspiration diagnosis of "Hürthle-cell neoplasm/follicular neoplasm with oncocytic features" denote increased risk of malignancy? Diagn Cytopathol. 2004;31(5):307-12.

16. Tuzun D, Ersoy R, Yazgan AK, Kiyak G, Yalcin S, Cakir B. Cytomorphologic features and ultrasonographic characteristics of thyroid nodules with Hurthle cells. Ann Diagn Pathol. 2015;19(3):175-9.

17. Kim TH, Lim JA, Ahn HY, Lee EK, Min HS, Won Kim K, et al.Tumor size and age predict the risk of malignancy in Hürthle cell neoplasm of the thyroid and can therefore guide the extent of initial thyroid surgery. Thyroid. 2010;20(11):1229-34.

18. Parikh PP, Allan BJ, Lew Jl. Surgeon-performed ultrasound predictors of malignancy in patients with Hü rthle cell neoplasms of the thyroid. J Surg Res. 2013;184(1):247-52.

19. Lee SK, Rho BH, Woo SK. Hürthle cell neoplasm: Correlation of gray-scale and power doppler sonographic findings with gross pathology. J Clin Ultrasound. 2010;38(4):169-76.

20. Maizlin Z V, Wiseman SM, Vora P, Kirby JM, Mason AC, Filipenko $D$, et al. Hurthle cell neoplasms of the thyroid: sonographic appearance and histologic characteristics. J Ultrasound Med. 2008;27(5):751-7; quiz 759.

21. Rago T, Di Coscio G, Basolo F, Scutari M, Elisei R, Berti P, et al. Combined clinical, thyroid ultrasound and cytological features help to predict thyroid malignancy in follicular and Hürthle cell thyroid lesions: Results from a series of 505 consecutive patients. Clin Endocrinol (Oxf). 2007;66(1):13-20.

22. Tessler FN, Middleton WD, Grant EG, Hoang JK, Berland LL, Teefey SA, et al. ACR Thyroid Imaging, Reporting and Data System (TI-RADS): White Paper of the ACRTI-RADS Committee. J Am Coll Radiol. 2017;14(5):587-95.

23. Ito $Y$, Hirokawa M, Miyauchi A, Kihara M, Yabuta T, Masuoka H, et al. Diagnosis and surgical indications of oxyphilic follicular tumors in Japan: Surgical specimens and cytology. Endocr J. 2016;63(11):977-82.

24. Lee KH, Shin JH, Ko ES, Hahn SY, Kim JS, Kim JH, et al. Predictive factors of malignancy in patients with cytologically suspicious for Hurthle cell neoplasm of thyroid nodules. Int J Surg. 2013;11(9):898-902.

25. Sippel RS, Elaraj DM, Khanafshar E, Zarnegar R, Kebebew E, Duh Q-Y, et al. Tumor Size Predicts Malignant Potential in Hürthle Cell Neoplasms of the Thyroid. World J Surg. 2008;32(5):702-7.

26. Jeh SK, So LJ, Bum SK, Yoen SL. Evaluating the degree of conformity of papillary carcinoma and follicular carcinoma to the reported ultrasonographic findings of malignant thyroid tumor. Korean J Radiol. 2007;8(3):192-7.

27. Rago T, Di Coscio G, Basolo F, Scutari M, Elisei R, Berti P, et al. Combined clinical, thyroid ultrasound and cytological features help to predict thyroid malignancy in follicular and Hrthle cell thyroid lesions: results from a series of 505 consecutive patients. Clin Endocrinol (Oxf). 2007;66(1):13-20.

28. Brito JP, Gionfriddo MR, Al Nofal A, Boehmer KR, Leppin AL, Reading $\mathrm{C}$, et al. The Accuracy of Thyroid Nodule Ultrasound to Predict Thyroid Cancer: Systematic Review and Meta-Analysis. J Clin Endocrinol Metab. 2014;99(4):1253-63.

29. Park JW, Kim DW, Kim D, Baek JW, LeeYJ, Baek HJ. Korean Thyroid Imaging Reporting and Data System features of follicular thyroid adenoma and carcinoma: a single-center study. Ultrasonography. 2017;36(4):349-54. 